\title{
Branchial Skeleton of the Landlocked "Ayu", Plecoglossus altivelis Temminck et Schlegel
}

\author{
Tamotsu IWAI \\ (Department of Fisheries, Kyoto University)
}

Although CHAPMAN (1941), working with the adult specimens, presented a comprehensive description on the skeletal system of the salmonoid fish, Plecoglossus altivelis T. \& S., The autho redescribes here the skeletal structure of the branchial apparatus of landlocked form in order to discuss the relationship between the branchial structure and feeding habits .of this species. Since, in this paper, particular attention was paid to making detailed account of the pharyngeal teeth and gill-rakers, which were rather briefly treated by CHAPMAN (1941), it may serve to supplement his description.

The author wishes to express sincere gratitude to Prof. K. Matsubara, under whose direction this investigation was undertaken.

Materials examined: All specimens upon which the present study is based were obtained from Lake Biwa. Of these, the young fish of standard length less than $40.0 \mathrm{~mm}$. were secured through the courtesy of the Shiga Prefectural Fisheries Experiment Station, and remaining materials were collected by the author. The preparations for osteological ebservations were made from 6 specimens measuring $55.5-71.5 \mathrm{~mm}$. in standard length: For the counts of gill-rakers 110 specimens, $21.5-75.0 \mathrm{~mm}$. in standard length, were employed.

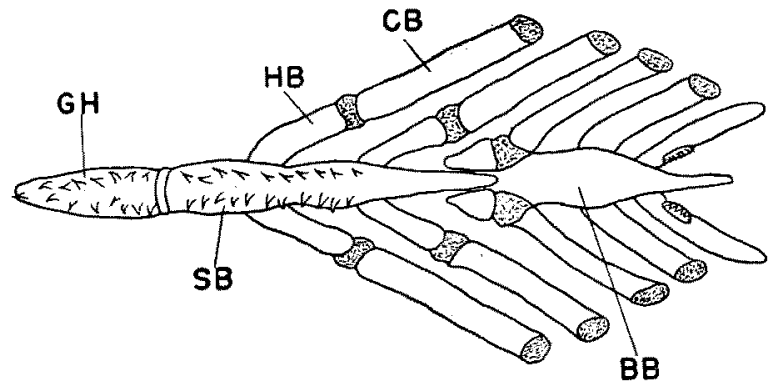

Fig. 1. Dorsal view of detached lower half of branchial arches of the $65.5 \mathrm{~mm}$. (standard length) specimen. BB. basibranchial ; CB. ceratobranchial ; GH. glossohyal; HB. hypobranchial ; SB. suprabasal bone.

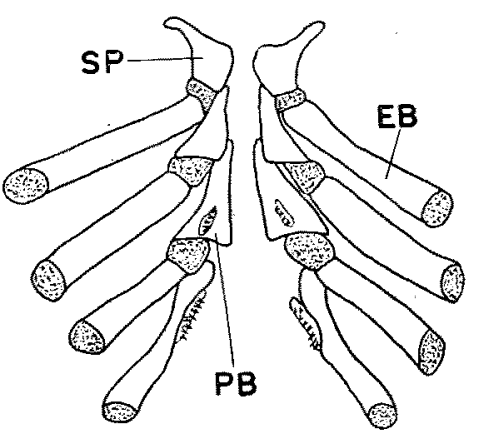

Fig. 2. Ventral view of upper half of the branchial arches of the $65.5 \mathrm{~mm}$. specimen. EB. epibranchial; $\mathrm{PB}$. pharyngo. branchial; SP. suspensory pharygeal.

Branchial arches (Figs. 1 and 2): The branchial apparatus is composed of five branchial arches diminishing in size posteriorly. The median floor of the arch is composed 
of four basibranchials which lie longitudinally behind the glossohyal. Anterior three basibranchials are short rod in shape, and they are hidden in the dorsal view by the so called suprabasal bone (CHAPMAN, 1941) which bears small conical teeth in two rows as is the case with the glossohyal (Fig. 1, SB). The fourth one is a flat, slender plate having a cartilaginous projection at the posterior end. There are hypobranchials on the anterior three arches. The first bone is a slender bar and anterior edge is inserted between the first and second basibranchials. The second one is as long as first one and inserted between the second and third basibranchials. Likewise, the third hypobranchial, about half as long as the former two, fits between the third and fourth basibranchials. Both fourth and fifth arches do not contain the hypobranchial. There are five pairs of ceratobranchials : anterior three of which articulate with the posterior end of respective hypobranchials, and the remaining two articulate with fourth basibranchial directly. All are of nearly the same length, and extend upward and backward to the angle of the arch. There is a small patch of minute conical teeth on the proximal side of the anterior end of each fifth ceratobranchial. This is not consonant with the previous literature, in which a lack of pharyngeal teeth is described for Plecoglossus (e.g. Chapman, 1941).

There are four pairs of epibranchials which articulate anteriorly with the pharyngobranchials (suprabranchials). A small patch of minute teeth is present on the proximal end of fourth epibranchial. There are four pairs of the pharyngobranchials. The first, usually termed as the suspensory pharyngeal, is strongly recurved at the distal end whereby it articulates with the cranium. The second and third are triangular in shape. The third one bears reduced patch of small teeth on the posterior extremity. The fourth is so reduced hat is obscure in ventral view. Consequently, the fourth epibranchial is attached to the third epibranchial at each anterior edge.

Gill-rakers : Along the anterior margin of each gill-arch a series of slender gill-rakers is arranged. Each raker is rather attenuate, and tapering gradually into a pointed tip. It is longest near the angle of the arch and progressively becomes shorter toward the distal ends of both upper and lower limbs. Counts of gill-rakers on the first gill-arch vary rather extensively with the size of the fish, i. e. there are $18(5+13)$ rakers in a specimen of $21.5 \mathrm{~mm}$. long (standard length), whereas $36(14+22)$ ones in a specimen measuring $75.0 \mathrm{~mm}$. It will be observed that the gill-rakers increase in number gradually with the growth of fish in both upper and lower limbs (Fig. 3). A $75.0 \mathrm{~mm}$. specimen has several less rakers on each limb than the full complement of the adult fish,

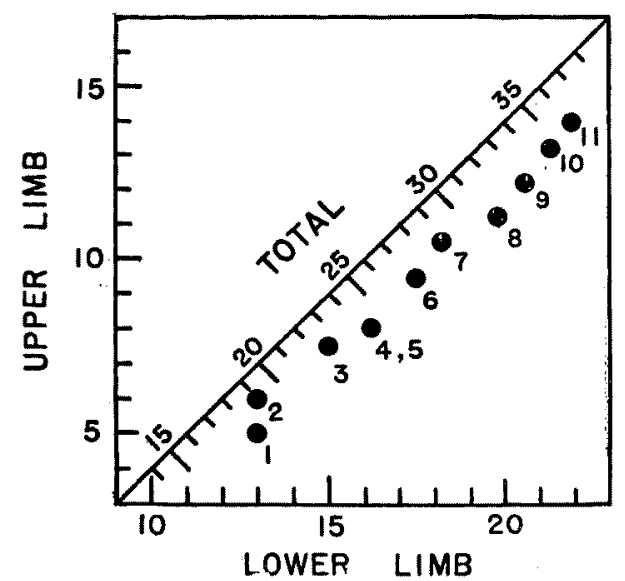

Fig. 3. Increase in number of gill-rakers on the first gill-arch with growth of the landlocked Plecoglossus. Each black circle is the average value of 10 specimens.

1. 21.5-25. $0 \mathrm{~mm}$. in standard length ;

2. 25.1-30.0 mm. ; 3. 30. $1-35.0 \mathrm{~mm}$. ;

4. $35.1-40.0 \mathrm{~mm}$; 5. 40.1-45.0 mm.;

6. $45.1-50.0 \mathrm{~mm}$.; 7. $50.1-55.0 \mathrm{~mm}$.;

8. $55.1-60.0 \mathrm{~mm}$; 9. $60.1-65.0 \mathrm{~mm}$.;

10. $65.1-70.0 \mathrm{~mm}$; 11. 70.1-75.0 $\mathrm{mm}$. 
which, according to CHAPMAN (1941), has $45(19+26)$. In their studies on the Pacific hake, Merluccius productus (Ayres), AHLstrom and Counts (1955) stated that the full complement of 18 gill-rakers $(4+14)$ is usually obtained by about $25.0 \mathrm{~mm}$. in length. It seems that formation of full complement of gill-raker in Plecoglossus is much delayec in comparison with that of the Pacific hake, though number of gill-rakers of the latter shows a considerable low value.

Considerations on the feeding habits: Two functions, respiration and a part of feeding, are attributed to the teleostean branchial apparatus. The gill-lamellae will serve the former function, and gill-rakers and pharyngeal teeth are chiefly dealt with the latter one. The latter relationships would be discussed below.

The evidence is overwhelming that there are two rather distinct feeding phases in the life history of Plecoglossus. These are characterized as follows: Young fish inhabiting the sea feed on zooplankton which strained out from the water. However, the diet of adult fish inhabiting the river is composed chiefly of such minute organisms as adherent diatoms (UEDA and OKADA, 1935; MIYADI, et al., 1952). In this study, no detailed analysis of the food is made on the landlocked form, but, insofar as author's observation is concerned, minute algae seemed to be important diet. Several special adaptations are to be recognized in Plecoglossus that make possible the peculiar feeding habits. The unique intraoral flap and comb-like teeth will serve as the example (MATSUI, 1936). The developing comb like teeth are first seen in young specimen of about $35.5 \mathrm{~mm}$. long (IwAI, 1956). With growth, the distinguishing characteristics of this dentition become enhanced. It is then completely arranged when the change is occurred in food habits from feeding on zooplankton to browsing on algae.

It is generally believed that the close-set gill-rakers are one of the striking characteristics of most micro-organism feeders. For example, the adult sardine, Sardinops melanosticta (T. \& S.) is furnished with more than 100 rakers on the first gill-arch (NAKAI, 1938) and the gizzard shad, Dorosoma cepedianum (LE SUEUR), has more than 300 (HUBBS and WhitLOCK, 1929). The great difference in raker counts between the sardine and Plecoglossus is exemplified. NAKAI (1938) found a sharp increase in number of gill-rakers of sardine, that is, there are 29 rakers in the $24.3 \mathrm{~mm}$. specimen, 50 rakers in the $37 \mathrm{~mm}$. specimen, 96 rakers in the $94 \mathrm{~mm}$. specimen, and 100 rakers in the $108 \mathrm{~mm}$. specimen respectively. As may be judged from Fig. 3, Plecoglossus shows consistently lower value of counts than that of the sardine for each stage of the growth. Notwithstanding rather raker coarse mesh of gill-rakers, Plecoglossus is capable of procuring a minute food. It is suggested that the feeding mechanism of this species may be aided by the extraordinary development of comb-like teeth which facilitate the obtaining minute adherent diatoms.

As already noted above, although CHAPMAN (1941) reported a nothing of teeth on the fifth ceratobranchials or on the pharyngobranchials, the much reduced teeth are assumed on either bone of the landlocked form. In almost cases for which descriptions are available, the voracious feeders bear highly developed pharyngeal teeth and micro-organisms feeders have reduced one. Accordingly, it may be surmised that the reduction of the pharyngeal dentition in Plecoglossus is closely related to its peculiarities of the feeding mechanism. 


\section{Ref erences}

Agrstrom, E. H. and R. C. Counts: U. S. Dept. Interior, Fish \& Wildife Serv., Fish. Bull., (99) : 295-329 (1955).

CEAPMAN, W. M.: Jour. Morph., 68 (3) : 425-455 (1941).

Hubss, C. L. and S. C. Whiтlock : Pap. Mich. Acad. Sci., Arts \& Letters, $10: 461-482$ (1929). IraI, T.: Bull. Jap. Soc. Sci. Fish., 22 (2) : 12-15 (1956).

Matsor, I. : Bot. \& Zool., 4 (11) : 1906-1912 (1936).

Miyadi, D., M. Kawabata and K. Ueda: Kyoto Univ. Fac. Sci. Contr. to Physiol. \& Ecol., (75) : $1-25$ (1952).

NAKaI, J.: Suisan Kenkyu-Shi, 33 (12) 547-561 (1938).

UEdA, S. and Y. OKadA: Bull. Jap. Soc. Sci Fish., 4 (4) : 233-238 (1935). 